Seminar Nasional Teknologi Informasi dan Kedirgantaraan (SENATIK)

Vol. II, 26 November 2016, ISSN: 2528-1666

\title{
Performa Pembakaran Kompor Biogas Menuju Desa Mandiri Energi di Yogyakarta
}

\author{
Kris Hariyanto ${ }^{1}$, Benedictus Mardwianta ${ }^{2}$ \\ Program Studi Teknik Mesin, \\ Sekolah Tinggi Teknologi Adisutjipto Yogyakarta, Jl Janti Blok R Lanud Adisutipto, \\ ${ }^{1}$ krishariyanto76@gmail.com, 2aries2144@yahoo.com
}

\begin{abstract}
Biogas is an alternative energy sources as a substitute for fossil fuels in household activities daily, but there are obstacles in the use of biogas, namely the difficulty of arranging a flame that is stable and fuel consumption relatively less efficient biogas. So it takes a design development system that will produce a burning stove produces biogas-fueled stove fits the purpose of research, on the other hand biogas stove should be simple, cheap production price, maximum efficiency and safe to use. Stages in the study include: desk assessment, creation of objective requirements desing, manufacture conceptual and basic design, manufacture real stove. As for knowing the performance of the stove carried ujji stove performance are: test flame stability and efficiency. The results showed that the efficiency of the biogas stove design results in only 31 percent higher than the efficiency of biogas stoves old design, while the fuel consumption of biogas stoves new design is 16 percent lower when compared with fuel consumption of biogas stoves old design. In terms of manufacture and ease of repair and maintenance of gas cookers new design is more easily repaired and easy to make and simple in form compared with the old design biogas stoves.
\end{abstract}

Keywords: design, efficiency, biogas stoves, fuel consumption

\section{Pendahuluan}

Sepanjang tahun 2010 sampai dengan 2011 Kementrian Lingkungan Hidup telah membantu penerapan teknologi biogas di beberapa sentra ternak sapi di dua kabupaten Daereah istimewa Yogyakarta, yaitu kabupaten Kulon Progo dan Kabupaten Bantul dengan biaya dari APBN. Sesuai dengan road map pengembangan energi terbarukan propinsi DIY target tahun 2025 biogas 5000 unit terpasang dan Desa Mandiri Energi (DME) dan sesuai dengan rencana umum energi daerah (RUED) propisni DIY kecamatan Berbah merupakan salah satu wilayah yang potensi untuk pengembangan biomassa (biogas) sebagai sumber energi alternatif.

Saat ini sudah hampir 25\% dari jumlah penduduk di desa tersebut menggunakan kompor berbahan bakar biogas, dimana system pembakaran ini digunakan utuk keperluan memasak seharihari, namun terdapat sebuah kendala yaitu sulitnya mengatur nyala api biogas agar stabil dan penggunaan biogas yang relatif kurang efisien jika dilihat dari konsumsi pemakaian bahan bakar dengan kandungan metana yang rendah [1] Untuk mencari penyelesian permasalahan tersebut, perlu diadakannya penelitian lebih lanjut mengenai sistem pembakaran efisien yang dihasilkan oleh kompor berbahan bakar biogas

Parameter dimensi terpenting dari desain burner biogas adalah sebagai berikut [2]-[4] :

- Diameter jet $\left(\mathrm{d}_{\mathrm{o}}\right)$

- Panjang lubang masukan angin diukur dari ujung jet $\left(\mathrm{L}_{\text {maks }}\right)$

- Panjang dari mixing pipe (L)

- Jumlah dan diameter lubang port burner $\left(\mathrm{d}_{\mathrm{H}}\right)$

- Tinggi dari kepala burner $(\mathrm{H})$

- Diameter Jet (d $)$

$d_{o}=2.1 \sqrt{V_{f} / \sqrt{h}}(\mathrm{~mm})$ 
- Dimana $\mathrm{V}_{\mathrm{f}}$ adalah laju aliran bahan bakar (m3/ jam) diperoleh dari persamaan (2)

$Q=V_{f}=c \sqrt{\Delta p d^{5} / S L}$

Dimana:

$\mathrm{d}=$ diameter selang karet

$\Delta \mathrm{p}=$ dihitung dari manometer

$\mathrm{S}=$ massa jenis udara $=1.2 \mathrm{~kg} / \mathrm{m}^{3}$

$\mathrm{L}=$ jarak antara manometer

- Diameter mixing pipe (d)

$$
\mathrm{d}=6 \mathrm{~d}_{0}
$$

- Panjang lubang masukan udara (L)

$$
\begin{aligned}
& \mathrm{L}_{\text {maks }}(\mathrm{mm})=7 \mathrm{~d} \\
& \mathrm{~L}_{\text {min }}(\mathrm{mm})=1.35 \mathrm{~d}
\end{aligned}
$$

- Diameter mixing chamber (D)

$$
\mathrm{D}(\mathrm{mm})=1.30 \mathrm{~d}
$$

- Panjang mixing chamber (L)

- $\quad \mathrm{L}=1.50 \mathrm{D}$

- Jumlah lubang burner (n)

$$
\mathrm{n}=20 \mathrm{do}^{2}
$$

- $\quad$ Diameter lubang port burner $(\mathrm{dH})$

$$
\mathrm{dH}=2.5 \mathrm{~mm}
$$

- Sedangkan untuk efisiensi sebagai berikut :

$$
\begin{array}{r}
C_{r}=\frac{q \text { ty of commodity }(\mathrm{g} \text { or } \mathrm{l})}{\text { time taken }(\mathrm{min})} \\
Q\left(\mathrm{~m}^{3} / \mathrm{h}\right)=c \sqrt{\frac{\Delta p(\mathrm{~cm}) d^{5}(\mathrm{~cm})}{S L(\mathrm{~m})}}
\end{array}
$$

- Dimana :

$$
\begin{aligned}
\mathrm{Q} & =\text { quantitas aliran udara }\left(\mathrm{m}^{3} / \mathrm{jam}\right) \\
\mathrm{c} \quad & \text { penurunan tekanan pada pipa, untuk } \\
& \text { pipa plastik halus } \mathrm{c}=2.80 \\
\Delta \mathrm{p} \quad= & \text { penurunan tekanand }=\text { diameter hose } \\
\mathrm{S} \quad= & \text { massa jenis udara } \\
\mathrm{L} \quad= & \text { jarak antara manometer }
\end{aligned}
$$

Sehingga efisiensi sebuah burner dapat digunakan dengan persamaan berikut ini :

$$
\eta=\frac{C_{r}}{Q}=\frac{\text { equation } 8}{\text { equation } 9} \times 100 \%
$$

\section{Metode Penelitian}

Penelitian dilakukan dengan menggunakan metode kualitatif untuk memenuhi tujuan dari penelitian berupa data yang menunjukkan peningkatan kualitas hasil pembakaran atau performa dari kompor biogas.

\subsection{Metode Pengumpulan Data}

Data awal sebagai referensi penelitian dilakukan dengan melakukan pengamatan terhadap kompor biogas yang saat ini banyak beredar di pasaran dan sering digunakan oleh masyarakat. Setelah itu dilakukan pengujian performa kompor tersebut untuk kemudian ditentukan bagian yang harus dilakukan modifikasi. Selain itu juga dilakukan pengambilan data melalui kuesoner yang diberikan kepada masyarakat yang telah menggunakan kompor berbahan bakar biogas.

Selanjutnya adalah melakukan desain kompor biogas menggunakan persamaan di atas sehingga diperoleh dimensi kompor tersebut.

Adapun modifikasi yang dilakukan adalah dengan memvariasi arah sudut pancar pada kepala burner menjadi tiga variasi yaitu horizontal, $45^{\circ}$ dan vertikal, seperti terlihat pada gambar berikut :

\section{IIIIIIIIIIIIIII}

Gambar 1. Burner cup dengan arah lubang vertikal

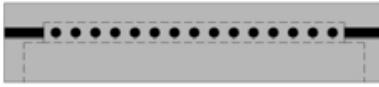

Gambar 2. Burner cup dengan arah lubang horisontal

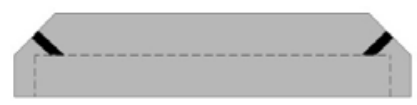

Gambar 3. Burner cup dengan arah lubang $45^{\circ}$

Setelah itu dilakukan proses manufakturing sehingga hasil Dari desain teknis tersebut kemudian dilanjutkan proses manufaktur dan setelah itu dilakukan uji fungsi untuk mengetahui performa kompor biogas tersebut. Instalasi pengujian performa kompor biogas dapat dilihat pada gambar berikut :

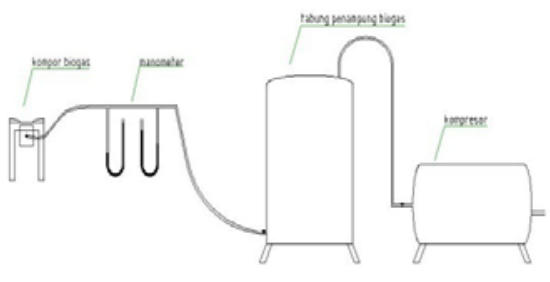

Gambar 4. Instalasi percobaan 
Pada setiap pengujian, hal yang perlu dilakukan adalah pengukuran dan pencatatan meliputi efisiensi kompor biogas dan stabilitas nyala api. Pengujian dilakukan untuk memasak 1 liter beras dan 1 liter air, dimana untuk waktu pemasakan dicatat.

\subsection{Metode Analisis Data}

Data yang diperoleh dari pengumpulan data selanjutnya di analisa secara kualitatif dengan melakukan pencatatan hasil melalui uji fungsi dari kompor biogas tersebut sehingga diketahui performanya dan data tersebut kemudian ditampilkan dalam bentuk tabel serta grafik sehingga akan mudah dalam melakukan analisa.

\section{Hasil dan Pembahasan}

Desain teknis dari kompor biogas didapatkan dengan melakukan perhitungan dimensi sehingga di dapatkan dimensi kompor sebagai berikut[4] :

Tabel 1. Hasil perhitungan awal dimensi kompor biogas

\begin{tabular}{|l|l|}
\hline $\begin{array}{l}\text { Nama Komponen } \\
\text { kompor }\end{array}$ & Dimensi \\
\hline Mixing tube & $127.5 \mathrm{~mm}$ \\
\hline Tinggi kompor & $90 \mathrm{~mm}$ \\
\hline Tinggi cup & $20 \mathrm{~mm}$ \\
\hline Diameter cup & $96 \mathrm{~mm}$ \\
\hline Jumlah lubang api & $35 \mathrm{lubang}$ \\
\hline Tinggi rangka pendukung & $200 \mathrm{~mm}$ \\
\hline Lebar rangka kompor & $200 \mathrm{~mm}$ \\
\hline
\end{tabular}

Desain teknis kompor biogas adalah sebagai berikut :

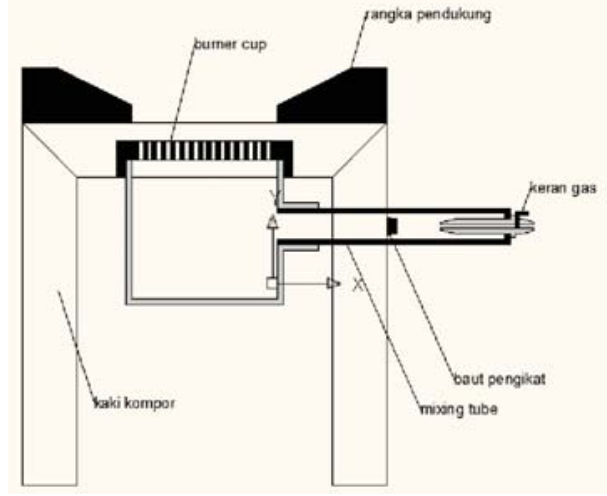

Gambar 5. Tampak atas desain kompor hasil perhitungan.

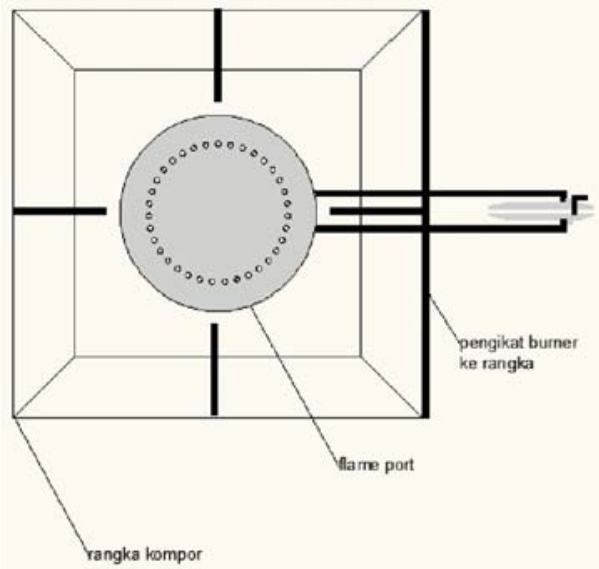

Gambar 6. Tampak atas desain kompor hasil perhitungan

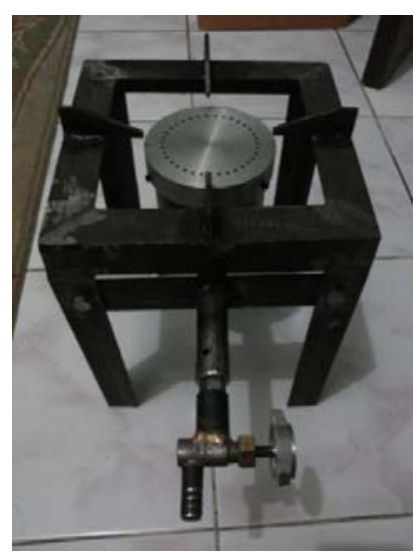

Gambar 7. Foto kompor setelah dirakit

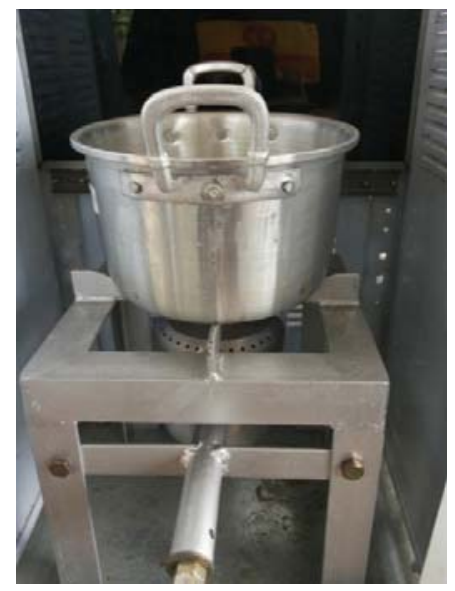

Gambar 8. Foto kompor biogas yang sudah di finishing 


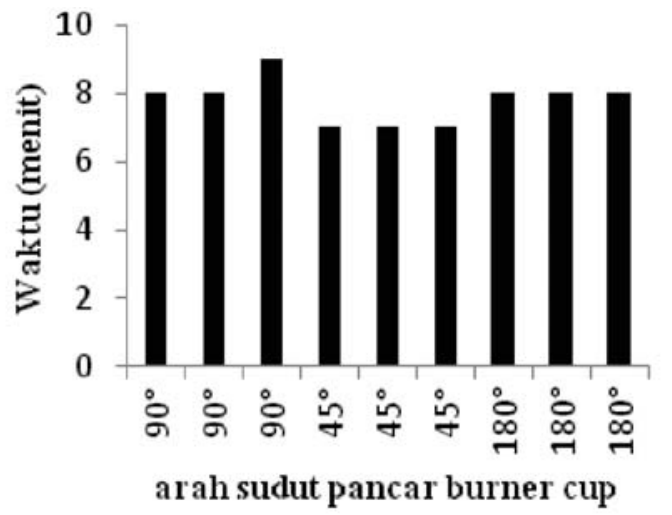

Gambar 9. Grafik perbandingan waktu yang dibutuhkan untuk mencapai $100^{\circ} \mathrm{c}$ masing-masing pengujian

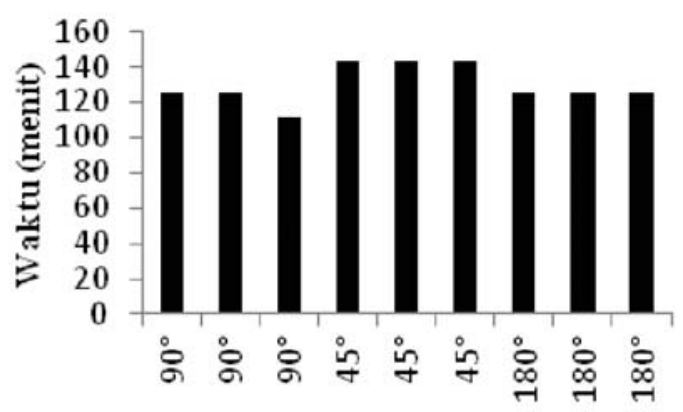

Arah sudut pancar burner cup

Gambar 10. Grafik perbandingan memasak untuk mendidihkan air masing-masing percobaan

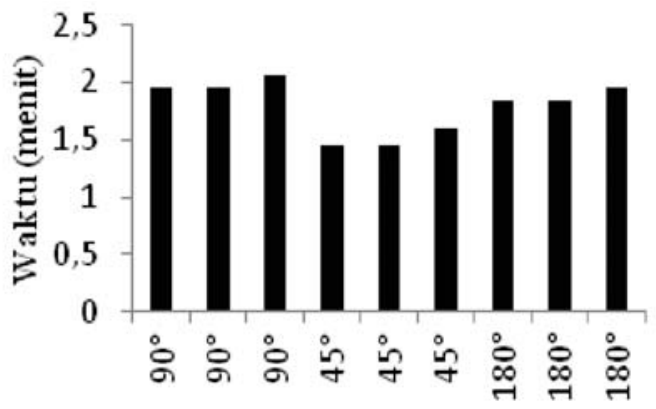

Arah sudut pancar burner cup

Gambar 11.Grafik perbandingan konsumsi biogas untuk mendidihkan air masing-masing percobaan

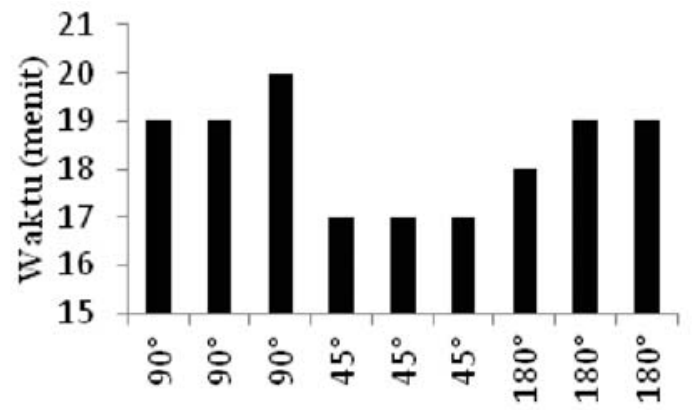

Arah sudut pancar burner cup

Gambar 12.. Grafik perbandingkan waktu yang dibutuhkan untuk mematangkan beras $150 \mathrm{~g}$

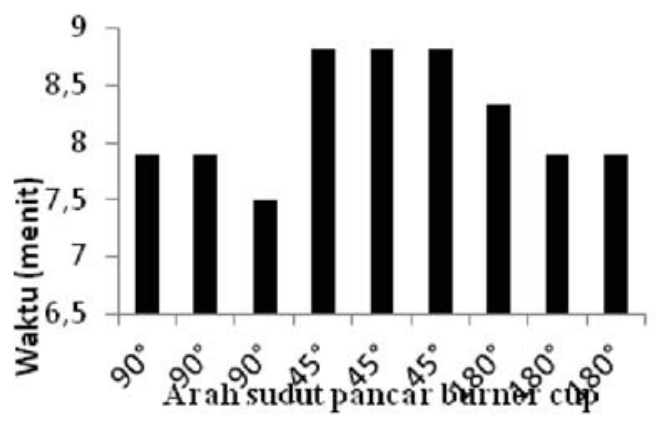

Gambar 13. Grafik perbandingan tingkat memasak untuk mematangkan $150 \mathrm{~g}$ beras

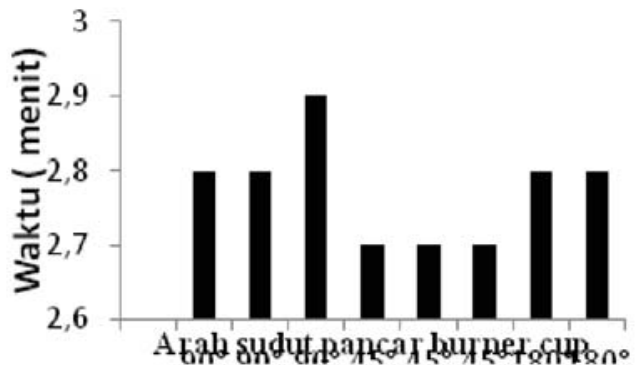

Gambar 14. Grafik perbandingan konsumsi biogas untuk mematangkan $150 \mathrm{~g}$ beras

Dari grafik tersebut terlihat dengan jelas bahwa untuk mendidihkan air dan memasak beras, waktu yang dibutuhkan untuk mencapai kondisi air mendidih dan beras masak paling cepat di dapat dari hasil pembakaran menggunakan burner cup yang 
lubang pancarnya membentuk sudut $45^{\circ}$ disusul selanjutnya oleh burner cup vertikal dan burner cup horisontal memerlukan waktu paling lama untuk mendidihkan atau memasak beras hingga masak.

Untuk konsumsi penggunaan biogas selama proses untuk mendidihkan air dan memasak beras, burnercup dengan sudut $45^{\circ}$ memerlukan kuantitas biogas yang relatif paling sedikit, disusul oleh burner cup horisontal dan konsumsi biogas paling banyak dihasilkan oleh burner cup vertikal. Hal tersebut terjadi karena pada burner cup vertikal, panas hasil pembakaran terfokus pada bagian tengah bidang pemanasan pada panci sehingga waktu yang dibutuhkan untuk memanaskan seluruh bidang pemanasan lebih lama sehingga konsumsi biogas yang diperlukan juga relatif lebih banyak.

Pembahasan tersebut di dukung oleh hasil observasi nyala api yang dihasilkan oleh ketiga arah lubang pancar burner cup. pada burner cup yang mempunyai arah lubang pancar vertikal terlihat nyala api relatif lebih tinggi apabila dibandingkan dengan burner cup yang memiliki arah lubang pancar horisontal dan $45^{\circ}$, hal tersebut mengindikasikan bahwa konsumsi penggunaan biogas selama pemakain relatif lebih banyak. Sedangkan pada burner cup yang memiliki sudut pancar horisontal memiliki ketinggian nyala api relatif paling rendah, hal tersebut dikarenakan jarak aliran masukan hingga keluar menjadi nyala api relatif lebih panjang, sehingga penggunaan konsumsi bahan bakar relatif lebih banyak, namun jika dibandingkan dengan burner cup dengan arah lubang pancar vertikal terlihat konsumsi bahan bakar biogas relatif lebih sedikit untuk melakukan kerja, hal tersebut disebabkan karena nyala api berada pada diameter terluar dari burner cup sehingga nyala api yang dihasilkan mempunyai radius relatif lebih besar dan dapat memenuhi panas yang diperlukan oleh bidang pemanasan. Sedangkan untuk burner cup dengan arah lubang pancar $45^{\circ}$ ketinggian nyala api yang dihasilkan lebih tinggi jika dibandingkan dengan burner cup dengan sudut pancar horisontal.

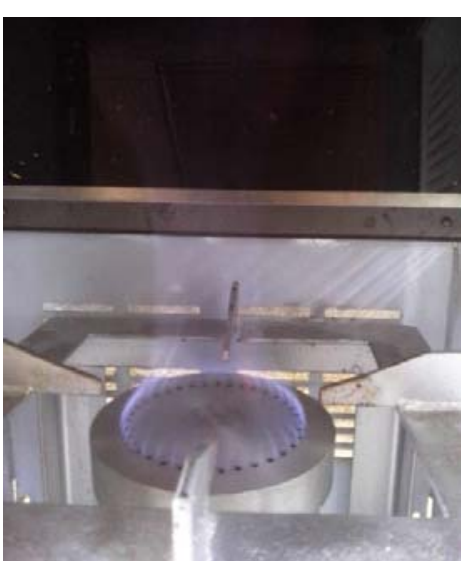

Gambar 15. Foto nyala api burner cup lubang pancar vertikal

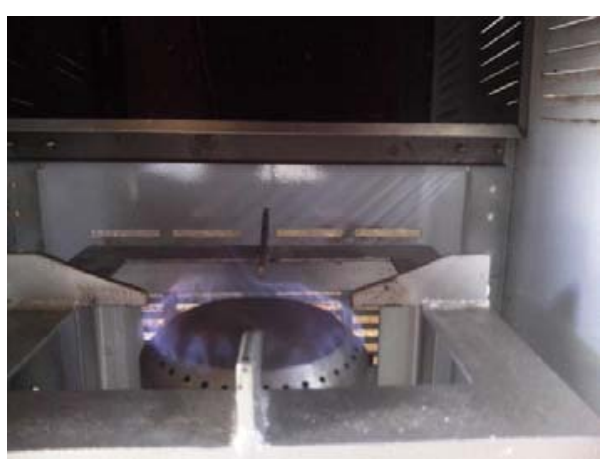

Gambar 16. Foto nyala api burner cup lubang pancar $45^{\circ}$

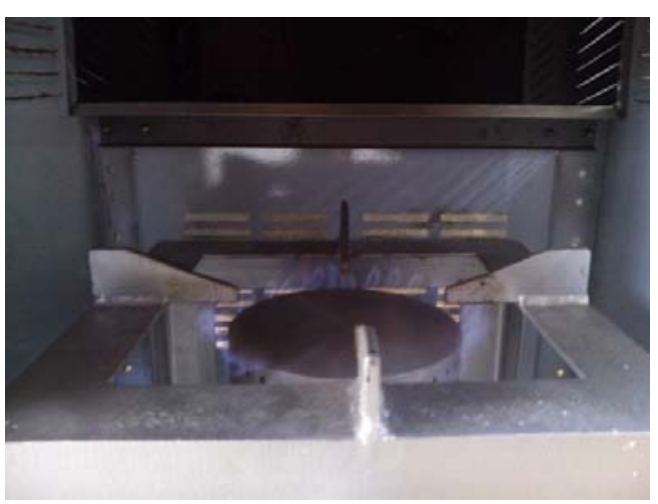

Gambar.17. Foto nyala api burner cup lubang pancar horisontal. 


\section{Kesimpulan}

Berdasarkan pembahasan di atas, maka dapat diambil kesimpulan sebagai berikut :

Penggunaan kompor biogas dengan burner cup arah pancar $45^{\circ}$ relatif mampu mengurangi penggunaan konsumsi bahan bakar biogas dan waktu untuk memasak apabila dibandingkan dengan kompor gas yang menggunakan burner cup arah pancar vertikal dan horisontal sehingga efisiensi pembakaran relatif lebih baik. Stabilitas dan nyala api kompor gas dengan burner cup arah pancar $45^{\circ}$ relatif lebih stabil dibandingkan dengan kompor gas yang menggunakan burner cup vertikal dan horisontal

\section{Ucapan Terima kasih}

1. Terima kasih kepada Direktorat Riset dan Pengabdian masyarakat, Kementrian Riset, Teknologi dan Pendidikan Tinggi yang telah mendanai penelitian ini sesuai dengan Surat Penugasan Pelaksanaan Penelitian (SP3) Disentralisasi Dikti Nomor: 029/HB-LIT/ III/2016 tgl 15 Maret 2016.

2. Terima kasih kepada KP4UGM yang telah memperbolehkan melakukan pengambilan data.

3. Terima kasih kepada masyarakat Berbah khususnya Dusun Blendangan yang berkenan memberikan keterangan mengenai penggunaan instalasi biogas.

\section{DAFTAR PUSTAKA}

[1] A. Sugiyono,2010, "Pengembangan Energi Alternatif di Derah Istimewa Yogyakarta: Prospek Jangka Panjang," in Proceeding Call for Paper Seminar Nasional VI Universitas Teknologi Yogyakarta, pp. 1-13.

[2] T. Al Seadi, D. Rutz, H. Prassl, M. Köttner, T. Finsterwalder, S. Volk, and R. Janssen,2008, Biogas handbook. Esbjerg: University of Southern Denmark Esbjerg.

[3] "Engineering design and economic evaluation of a family-sized biogas project in Nigeria." [Online]. Available: http://www.sciencedirect. com/science/article/pii/S0166497299001054. [Accessed: 12-Sep-2015].

[4] I. N. Itodo, G. E. Agyo, and P. Yusuf,2007, "Performance evaluation of a biogas stove for cooking in Nigeria," J. Energy South. Afr., vol. 18 , no. 3 , p. 15 . 